\title{
La desamortización eclesiástica y el destino de los conventos suprimidos en Murcia
}

\author{
JoAquín MARTínez PINO*.
The disentailment of the ecclesiastical property and the destiny of the disappeared monasteries in Murcia.

RESUMEN

En este artículo se atiende la normativa desamortizadora del siglo XIX y su vinculación con la aparición de una conciencia de tipo patrimonial en España. Se trata igualmente el destino de los conventos suprimidos, con especial atención la ciudad de Murcia.

PALABRAS CLAVE

Desamortización, Patrimonio Cultural, Comisiones Científico Artísticas, Comisiones Provinciales de Monumentos,
SUMMARY

This article deals with the disentailment legislation of 19th century. It also establishes a link between that and a new heritage consciousness in Spain. Lastly, the destiny of disappeared monasteries is discussed here, paying special attention to city of Murcia.

KEY WORDS

Disentailment, Cultural Heritage, Scientific and Artistic Commissions, Provincial Commissions of Monuments, Murcia

Cuando en septiembre de 1833 muere Fernando VII, su hija Isabel no contaba todavía con tres años de edad. Su madre, Maㅡ Cristina de Borbón, asumió la regencia en tanto Isabel no alcanzase al mayoría de edad. Desde el primer momento, su trono se vio amenazado por las pretensiones de D. Carlos, quien se negó a acatar la Pragmática Sanción de 1830, que le relegaba en la línea sucesoria. El infante contaba con el apoyo de los grupos más apegados a la tradición absolutista y con la simpatía de las potencias legitimistas o absolutistas de Austria, Prusia y Rusia. La Regente se vio obligada a buscar el apoyo de los grupos liberales, forjando una alianza que, entre 1834 y 1840, dio lugar a una transformación del Estado en un doble proceso: político, con la implantación de una monarquía constitucional; y económico, con la adopción de una serie de medidas desamortizadoras que trasformaron los fundamentos heredados del antiguo régimen.

*Profesor de Historia del Arte, UNED, jmpino@geo.uned.es. 
El Estatuto Real de 1834 reguló el procedimiento de Cortes y estableció la creación de dos cámaras. Más tarde, la Constitución de 1837 concilió la relación de poderes entre Corona y Cortes, conjugando la afirmación del poder Real con las aspiraciones progresistas, desembocando en un sistema en el que la Corona mantenía el poder ejecutivo, pero cedía un mayor poder político al Gobierno y el Parlamento.

Las disposiciones desamortizadoras se dirigían a liberar la tierra de las llamadas manos muertas. El objetivo era favorecer la aparición de nuevas propiedades privadas que dinamizasen el mercado y proporcionasen mayores ingresos tributarios a la Hacienda Pública, más allá de los ingresos directos provenientes de la venta en subasta pública de unas tierras declaradas bienes nacionales.

\section{LA POLÍTICA DESAMORTIZADORA DURANTE EL PERIODO LIBERAL}

Es frecuente señalar que las desamortizaciones tuvieron un triple objetivo: político, económico y social. Social, porque privaba a los antiguos estamentos de su fuerza económica y preparaba la sustitución de la sociedad estamental por una sociedad de clases. Político, por cuanto aumentaba, en los beneficiarios de estas medidas, los partidarios del liberalismo, en contraposición a los absolutistas, identificados con el Carlismo, y contrarios a cualquier alteración del orden establecido. Económico, porque permitía hacer frente a la gran deuda acumulada ${ }^{1}$.

El propio Juan Álvarez Mendizábal justificaba en estos términos su disposición de 19 de febrero de 1936:

«Señora: Vender la masa de bienes que ha venido a ser propiedad de la nación, no es tan sólo cumplir una promesa solemne y dar una garantía positiva a la deuda nacional por medio de una amortización exactamente igual al producto de las rentas, es abrir una fuente abundantísima de felicidad pública; vivificar una riqueza muerta; desobstruir los canales de la industria y de la circulación; apegar al país por el amor natural y vehemente a todo lo propio; ensanchar la patria, crear nuevos y fuertes vínculos que liguen a ella; es en fin identificar con el trono excelso de Isabel II, símbolo de orden y libertad.

No es, Señora, ni una fría especulación mercantil, ni una mera operación de crédito, por más que ésta sea la palanca que mueve y equilibra en nuestros días las naciones de Europa: es un elemento de animación de vida y de ventura para España. Es, si puedo explicarme así, el complemento de su resurrección política.

El decreto que voy a tener la honra de someter a la augusta aprobación de V.M. sobre la venta de eses bienes adquiridos ya por la nación, así como en su resultado material ha de producir el beneficio de minorar la fuerte suma de la duda pública, es menester que en su tendencia, en su objeto y aun en los medios por donde aspire a aquel resultado, se enlace, se encadene, se funda en la alta idea de

${ }^{1}$ JOVER ZAMORA, J. M., GÓMEZ-FERRER, G. y FUSI AIZPURÚA, J. P., España: sociedad, política y civilización (siglos XIX y XX), Madrid, Debate, 2001, pág. 158. 
crear una copiosa familia de propietarios, cuyos goces y cuya existencia se apoye principalmente en el triunfo completo de nuestras actuales instituciones.»²

No obstante, el grado de relevancia de estos objetivos también ha sido discutido. Resulta lógico el deseo de ganar adeptos a la causa liberal, fundamentalmente entre las clases nobiliarias; o al menos, el intento de evitar enemigos. La nobleza, estamento que junto a la Iglesia detentaba la mayor parte de las tierras, no sólo no vio en peligro sus posesiones, sino que resultó ser la mayor beneficiaria de la operación mediante la compra masiva de terrenos nacionalizados. Resulta más endeble el argumento de crear una amplia base de pequeños propietarios. No se entiende, como señala Tomas y Valiente, «quién sería el "ser benéfico" que, teniendo dinero para comprar fincas para sí, fuera a prestárselo a algún jornalero insolvente» ${ }^{3}$. Por otra parte, el sistema de venta elegido — subasta pública, donde los bienes pasaban al mejor postor-, hacía muy difícil el reparto de tierras entre pequeños propietarios, lo que demuestra que Mendizábal no tenía como objetivo llevar a cabo una reforma agraria ${ }^{4}$. No se discute, en cambio, la apremiante necesidad económica por la que pasaba el Estado. En 1836 la deuda activa era de 1.500 millones de reales, y la presión de los acreedores cada vez mayor ${ }^{5}$. Por eso, coincidimos con Germán Rueda en que, sin negar la existencia de otras causas, que él denomina «difusas», Mendizábal pensaba, sobre todo, en resolver el problema de la hacienda ${ }^{6}$.

\section{Precedentes históricos}

La cuestión de la deuda pública es un problema que se remonta a la centuria anterior, especialmente a sus últimas décadas. Para Tomas y Valiente, gran parte de este dudoso mérito correspondía al Valido del Rey, Manuel Godoy, quien, en apenas quince años, condujo a España a una serie de costosísimas guerras que esquilmaron la hacienda: contra Francia (1793-1795), contra Portugal (1801-1803) y contra Inglaterra (1797-1801 y 1804-1808)7; a las que poco después se sumó la Guerra de la Independencia (1808-1814).

Por lo demás, las medidas desamortizadoras no fueron un invento liberal. En España, sus orígenes se remontan a los intentos de reforma agraria de Carlos III y

\footnotetext{
${ }^{2}$ R. D. de 19 de febrero de 1836, publicado en Gaceta de Madrid, n. 426, el 21 de febrero de 1836. Exposición a S.M. la Reina Gobernadora.

${ }^{3}$ TOMAS Y VALIENTE, El marco político de la desamortización en España, Barcelona, Ariel, 1971, pág. 79.

${ }^{4}$ MARTÍ GILABERT, F. La desamortización española, Madrid, Rialp, 2003, pág. 50.

${ }^{5}$ El propio embajador de Inglaterra habría apremiado a Mendizábal a incautarse las rentas de la Iglesia. JANKE, P. Mendizábal y la instauración de la monarquía constitucional en España (1790-1853), Madrid, Siglo XXI, 1974, pág. 234, citado en MARTí GILABERT, F., óp. Cit., pág. 43.

${ }^{6}$ RUEDA HERNANZ, G., «La desamortización en España: un balance (1766-1924)» Cuadernos de Historia, no 38, Madrid, Arco libros, 1997, pág. 45.

7 TOMAS Y VALIENTE, F., óp. cit., pág. 38.
} 
a los informes de intendentes y ministros como Pablo de Olavide o Jovellanos, que planteaban el perjuicio que suponía para la hacienda la amortización de tierras en poder de manos muertas, por sustraerse a tributos y obstaculizar la producción ${ }^{8}$. Sin embargo, conviene recordar que las propuestas de éstos y otros ilustrados solían ceñirse a los baldíos y propios concejiles. Existía una actitud dulcificada y comprensiva ante la Iglesia, con la que en todo caso se recomendaba proceder de forma negociada, a fin de evitar que siguiese acumulando tierras ${ }^{9}$.

Caso aparte es el de la Compañía de Jesús, expulsada de España mediante la Pragmática Sanción dictada por Carlos III, en abril de 1767, y suprimida por el Papa Clemente XIV en 1773. Sus bienes pasaron a la Hacienda Real, pero muchas de estas propiedades — las destinadas al culto, residencias de religiosos y colegios- no podían ser puestas en venta y continuaron sirviendo a sus fines bajo la dependencia de otras entidades ${ }^{10}$.

El problema de la Hacienda comienza a vincularse con la existencia de grandes propiedades durante el reinado de Carlos IV, periodo de mayor crecimiento de la deuda ${ }^{11}$.

Las Reales Cédulas de 23 mayo y de 24 de agosto de 1975 establecieron ciertos impuestos sobre las rentas de dignidades y canonjías, así como sobre la adquisición de nuevas propiedades ${ }^{12}$. Y en 1798 se destinaron -mediante tres Reales Órdenes de 25 de septiembre - a la recién creada Caja de Amortización ${ }^{1}$ las rentas de los Colegios Mayores y los bienes que quedaban de las temporalidades de los Jesuitas expulsados, así como el producto de la enajenación de bienes pertenecientes a hospitales, hospicios, casas de misericordia, de reclusión y expósitos, cofradías, memorias y obras pías y patronato de legos.

Esta es la base del proceso desamortizador del siglo XIX, caracterizado, como apuntaba Tomas y Valiente, por la «apropiación por parte del Estado y por decisión unilateral suya de bienes inmuebles pertenecientes a manos muertas; venta de los mismos, y asignación del importe obtenido con las ventas a la amortización de los títulos de la deuda» ${ }^{14}$.

\footnotetext{
${ }^{8}$ Sobre estos informes sobre la Ley Agraria de Olavide (1768) y Jovellanos (1794) encontramos un pequeño pero clarificador análisis en TOMAS Y VALIENTE, F., óp. cit., págs. 12-23.

${ }^{9}$ Tomás y Valiente observa que nadie, durante el siglo XVIII, propuso la desamortización de tierras pertenecientes a la Iglesia. Tan solo encontramos algunas tímidas reflexiones por parte de ministros como Francisco Carrasco, Campomanes o Floridablanca, que incidían en la necesidad de evitar que ésta siguiese adquiriendo tierras. TOMAS Y VALIENTE, F., óp. cit., pág. 23-31.

${ }^{10}$ RUEDA HERNANZ, G., óp. cit., pág. 27

${ }^{11}$ En 1808, según liquidación del Gobierno intruso, el importe de la deuda ascendía a más de 7.000.000.000 de reales. TOMAS Y VALIENTE, F., óp. cit., pág. 39. El autor toma la cita de CANGA ARQÜELLES, J. Diccionario de Hacienda, Madrid, 1833, t. I, págs. 339-340.

12 Ibídem, pág. 40.

${ }^{13}$ Mediante Real Cédula de 26 de febrero de 1798 se creaba una Caja de Amortización independiente de la Tesorería Mayor, en la que ingresarían todas las rentas y productos destinados a la amortización y pago de los vales reales.

14 TOMAS Y VALIENTE, F., óp. cit., pág. 44.
} 
El gobierno de José Bonaparte, acuciado por los gastos del conflicto, adoptó como propia la estrategia iniciada con Godoy, llegando con sus disposiciones a límites hasta entonces impensables ${ }^{15}$.

El 18 de agosto de 1809 aprobó un Real Decreto que suprimía las órdenes regulares monacales, mendicantes y clericales, y que aplicaba estos bienes a la Nación mediante su venta ${ }^{16}$. La disposición tuvo un efecto limitado. En primer lugar, porque sólo pudo ponerse en marcha en los pocos territorios donde el bonapartismo estaba asentado; $y$, en segundo lugar, porque todas las normas desamortizadoras fueron derogadas al regreso de Fernando VII. Sin embargo, como afirma Rueda, la importancia de esta disposición va más allá de sus efectos inmediatos: «la expulsión física [de las tropas francesas] no pudo terminar con muchas de las ideas que representaba, de las que quedaron sembradas las imprentas y las mentes de algunos de los españoles más influyentes ${ }^{17}$. Por otra parte, la experiencia madrileña, donde los numerosos derribos de conventos dieron paso a una importante reestructuración urbanística, permaneció como ejemplo para actuaciones emprendidas años más tarde ${ }^{18}$.

Mientras tanto, las Cortes de Cádiz, sin ir tan lejos, reconocían la necesidad de procurar nuevos ingresos. El Decreto de 13 de septiembre de 1813 vinculaba a los bienes nacionales aquellos confiscados a los traidores, los de las temporalidades de los Jesuitas y los de los conventos o monasterios destruidos durante la guerra o suprimidos por disposición del gobierno intruso. Lo mismo ocurría con los bienes de las órdenes militares de Santiago, Alcántara, Calatrava, Montesa y San Juan de Jerusalén, así como gran parte de las propiedades y sitios reales; y poco después con los procedentes de la extinta Inquisición ${ }^{19}$.

Respecto al clero regular, el Decreto de 17 de junio de 1812 estableció el secuestro de los bienes de las órdenes suprimidas por la disposición bonapartista de 18 de agosto de 1809. Para las Cortes de Cádiz se trataba de una medida provisional, con el objetivo de reintegrar los bienes a sus legítimos propietarios llegado el caso. No obstante, en opinión de Tomás y Valiente, muchos diputados estuvieron tentados de proclamar definitivos estos secuestros, y la idea quedó instalada en ellos.

\footnotetext{
${ }^{15}$ ANTIGÜEDAD DEL CASTILLO-OLIVARES, Ma․ D., El patrimonio artístico de Madrid durante el Gobierno Intruso (1808-1813). Madrid, Estudios de la UNED, 1999, pág. 50

${ }^{16}$ A este R. D. le habían precedido otras disposiciones que apuntaban a este fin. Entre ellas, en diciembre de 1808, Napoleón había ordenado reducir a un tercio los conventos españoles y confiscas los bienes del Santo Oficio; y en julio de 1809, se había establecido la puesta en venta de los bienes nacionales ya existentes para el pago de los intereses de la deuda pública. RUEDA HERNANZ, G., óp. cit., pág. 78

17 lbídem, pág. 35

${ }^{18}$ Podemos encontrar un amplio estudio sobre el destino de los conventos de Madrid en ANTIGÜEDAD DEL CASTILLO-OLIVARES, Ma․ D, óp. cit.

19 TOMAS Y VALIENTE, F., óp. cit., págs. 62-63.
} 
Sea como fuere, lo que se produjo a partir de este momento fue la vinculación de dos cuestiones hasta entonces inconexas: la reforma del clero secular y la desamortización de sus bienes ${ }^{20}$.

Como afirma Martínez Ruíz, nuestros años de guerra contra los franceses constituyen la primera etapa de la revolución liberal en España. La reacción absolutista contra el proceso revolucionario, encarnada por el propio Fernando VII, resultó finalmente «inútil», y sólo pudo posponer unos años lo que ya se había iniciado: el establecimiento del liberalismo ${ }^{21}$. Lo que nos interesa subrayar de este proceso es que, en todas estas etapas, las iniciativas desamortizadoras jugaron un papel de primer orden.

Así, durante el Trienio Progresista se restablecieron las disposiciones de Cádiz. La desamortización eclesiástica se retomó con el R. D. de 9 de agosto de 1820, que significaba el restablecimiento del Decreto de 13 de septiembre de 1813, incluyendo entre los objetos a enajenar los procedentes del Santo Oficio. Poco después, por Decreto de 1 de octubre de 1820, se suprimían «todos los monasterios de las órdenes monacales; los canónigos regulares de San Benito, de la congregación claustral tarraconense y cesaraugustana; los de San Agustín y los premonstratenses; los conventos y colegios de la Órdenes militares de Santiago, Calatrava, Montesa y Alcántara; los de la de San Juan de Jerusalén, los de la de San Juan de Dios y los betlemitas, y todos lo demás de hospitales de cualquier clase»; todos sus bienes quedaban aplicados al crédito público. Por último, el 11 de octubre se promulgaba de Ley de desvinculaciones, que suprimía todos los mayorazgos, fideicomisos, patronatos y cualquier otra vinculación de bienes; y que prohibía la adquisición de nuevos bienes a todo tipo de manos muertas ${ }^{22}$.

\section{Desamortización en época de Regencias}

Cuando $\mathrm{M}^{\mathrm{a}}$ Cristina asumió la Regencia, la deuda del Estado rondaba los 400 millones de reales —más de la mitad del presupuesto anual del Estado, según Rueda - y empezaba una guerra contra los partidarios de su tío y cuñado, Carlos María Isidro. La necesidad de hacer frente a estos gastos le obligó a acometer, ya de forma directa y en abierta oposición a la Iglesia, la postergada desamortización eclesiástica.

Las primeras medidas retomaron objetivos anteriores. Por R. D. de 15 de julio de 1834 se suprimía definitivamente la Inquisición —pese a la abolición anterior había continuado actuando como Juntas de Fe-; y el R. D. de 4 de julio de 1835

\footnotetext{
20 lbídem, pág. 64.

${ }^{21}$ MARTÍNEZ RUÍZ, E. La Guerra de la Independencia (1808-1814). Claves españolas en una crisis europea, Madrid, Sílex, 2007, págs. 265-266.

22 Ibídem, págs. 70-71.
} 
hacía lo propio con la Compañía de Jesús —restaurada por Pio VII en 1814 y en España desde 1915-.

Pocos días después, Mํㅡㄹ Cristina firma el R. D. de 25 de julio de 1835, por el que se suprimían «los monasterios y conventos de religiosos que no tengan 12 individuos profesos" - en total, más de 900 casas religiosas, casi la mitad de las existentes hasta el momento 23 - Y el 11 de octubre, un nuevo decreto ampliaba la medida a «...todos los monasterios de órdenes monacales; los de canónigos reglares de S. Benito de la congregación claustral Tarraconense y Cesaraugustana; los de S. Agustín y los Premostratenses, cualquiera que sea el número de monjes o religiosos de que en la actualidad se compongan". Por el momento quedaban exentos los monasterios benedictinos de Monserrat, S. Juan de la Peña y Valladolid; los de Jerónimos del Escorial y Guadalupe; el de S. Bernardo de Poblet; el de Cartujos de el Paular; y el de S. Basilio de Sevilla; aunque se les impedía dar nuevos hábitos o admitir a profesión a los novicios.

En 1836 aparecen nuevas medidas. El R. D. de 19 de febrero puso en venta «todos los bienes raíces de cualquier clase que hubieran pertenecido a las comunidades y corporaciones religiosas extinguidas, y los demás que hayan sido adjudicados a la nación por cualquiera título o motivo y también todos los que en adelante lo fueren desde el acto de su adjudicación ${ }^{25}$. Por su parte, el R. D. de 9 de marzo supuso la exclaustración de la práctica totalidad de los conventos y monasterios masculinos, y la apropiación para la Hacienda de todos sus bienes: "Art. 1․ Quedan suprimidos todos los monasterios, conventos, colegios, congregaciones y demás casas de comunidad o de instituto religioso de varones, inclusas las de clérigos seculares, y las de las cuatro órdenes militares y $S$. Juan de Jerusalén, existentes en la Península, islas adyacentes y posesiones de España en África. [...] ${ }^{26}$.

Un año más tarde el R. D. de 27 de julio de 1837 amplió la supresión a «todos los monasterios, conventos, colegios, congregaciones y demás casas de religiosos de ambos sexos ${ }^{27}$.

\footnotetext{
${ }^{23}$ R.D. de 25 de julio de 1835, publicado en Gaceta de Madrid, no 211, el miércoles 29 de julio de 1835.

${ }^{24}$ Se prohibía, además, la existencia en un mismo pueblo o término de más de un convento de una misma orden. R.D. de 11 de octubre de 1835, publicado en Gaceta de Madrid, no 292, el miércoles 14 de octubre de 1835.

${ }^{25}$ R.D. de 19 de febrero de 1836, publicado en Gaceta de Madrid, № 426, el domingo 21 de febrero de 1836.

${ }^{26}$ R.D. de 9 de marzo de 1836, publicado en Gaceta de Madrid, no 444, el jueves 10 de marzo de 1836. Señalaba además: «Art. 2 Se exceptúan de los dispuesto [...]1. Los colegios de misioneros para las provincias de Valladolid, Ocaña y Monteagudo, 2. Las casas de clérigos de las Escuelas Pías y los conventos de hospitalarios de S. Juan de Dios [...]; Art. 5 [...] 1. No se conservará abierto ningún convento que tenga menos de 20 religiosas profesas, 2 . No se permitirán en una misma población dos o más conventos de una misma orden.»

${ }^{27}$ R.D. de 29 de julio de 1837, publicado en Gaceta de Madrid, no 977, el viernes 4 de agosto de 1837.
} 
En 1841, bajo la regencia del General Espartero, el R. D. de 2 de septiembre ordenó la apropiación de todas las propiedades del clero secular28.

Finalmente, durante el Bienio progresista el propio General Espartero, desde el Gobierno, propició la última gran medida desamortizadora, que culminaba el trabajo iniciado por Mendizábal. La Ley de 1 de mayo de 1955, elaborada por Pascual Madoz, Ministro de Hacienda, era la más ambiciosa y la de mayor alcance de las medidas hasta ahora emprendidas, poniendo en venta «todos los predios rústicos y urbanos, censos y foros pertenecientes: Al Estado. Al clero. A las órdenes militares de Santiago, Alcántara, Calatrava, Montesa y San Juan de Jerusalén. A cofradías, obras pías y santuarios. Al secuestro del ex-infante don Carlos. A los propios y comunes de los pueblos. A la beneficencia. A la instrucción pública. Y cualquiera otros pertenecientes a manos muertas, ya estén o no mandado vender por leyes anteriores» ${ }^{29}$.

\section{LA PROTECCIÓN DE LOS BIENES HISTÓRICO-ARTÍSTICOS EN LA LEGISLACIÓN DESAMORTIZADORA.}

A pesar del importante perjuicio que supusieron para nuestro patrimonio las desamortizaciones y las guerras, durante el periodo isabelino se observa una creciente preocupación por conservar los bienes históricos y artísticos procedentes de los conventos suprimidos. De hecho, la propia normativa desamortizadora contenía las primeras disposiciones en este sentido.

El R. D. de 4 de julio de 1835, que suprimía la Compañía de Jesús, excluía de los bienes aplicados a la extinción de la deuda «las pinturas, bibliotecas y enseres que puedan ser útiles a los institutos de ciencias y artes, así como también los colegios, residencias y casas de la Compañía, sus iglesias, ornamentos y vasos sagrados, de los que me reservo disponer» (Art. 7). La misma fórmula se encuentra en el R. D. de 25 de julio de 1835: «Se exceptúan con todo de esta aplicación los archivos, bibliotecas, pinturas y demás enseres que puedan ser útiles a los institutos de ciencias y artes, así como también los monasterios y conventos, sus iglesias, ornamentos y vasos sagrados» (Art. 7).

Estas cláusulas requerían de una laboriosa tarea de inspección y recolección, que los gobernadores civiles provinciales no podía afrontar sin la ayuda de personas destinadas al efecto. Por ello, la R. O. de 29 de julio de 1835 mandó crear comisiones provinciales destinadas a «examinar, inventariar y recoger cuanto contengan los archivos y bibliotecas de los monasterios y conventos suprimidos, $y$ las pinturas, objetos de escultura u otros que deban conservarse» (Art. 1) ${ }^{30}$.

\footnotetext{
${ }^{28}$ R.D. de 2 de septiembre de 1841, publicado en Gaceta de Madrid, no 2515, el domingo 5 de septiembre de 1841. La norma estuvo vigente hasta julio de $1844^{29}$, derogada con la llegada al poder de los moderados. MARTí GILABERT, F., óp. cit., pág. 68.

${ }^{29}$ Ley de 1 de mayo de 1955, publicado en Gaceta de Madrid, n. 852, el jueves 3 de mayo de 1855.

${ }^{30}$ R.O. de 29 de julio de 1835, publicada en Gaceta de Madrid, no 217, el martes 4 de agosto de 1835.
} 
Los R. D. de 19 de febreroy de 9 de marzo de 1836 incluyeron nuevas normas. El primero exceptuaba de la venta «los edificios que el Gobierno destine para el servicio público, o para conservar monumentos de las artes, o para honrar la memoria de hazañas nacionales» (Art. 2). El segundo dictaba que: "Los ordinarios podrán, con la aprobación del Gobierno, dedicar a parroquias las iglesias de los conventos suprimidos que sean necesarias [Art. 22]; del mismo modo podrán disponer a favor de las parroquias pobres de sus diócesis de los vasos sagrados, ornamentos y demás objetos pertenecientes al culto, excepto aquellos que por su rareza o mérito artístico convenga conservar cuidadosamente, y los que por su considerable valor no correspondería a la pobreza de las iglesias [Art. 23]; podrán destinarse para establecimientos de utilidad pública los conventos suprimidos que se crean a propósito [Art. 24]; asimismo se aplicarán los archivos, cuadros, libros y demás objetos pertenecientes a los institutos de ciencia y artes, a las bibliotecas provinciales, museos, academias y demás establecimientos de instrucción pública [Art. 25].»

Desde fecha muy temprana se observaron dificultades para dar salida a los numerosos edificios conventuales, fundamentalmente a aquellos existentes en las ciudades, por lo que se procuró dar una solución rápida buscándoles una utilidad públi$\mathrm{ca}^{31}$. El R. D. de 25 de enero de 1836 dispuso que, en la ciudad de Madrid, se pusieran todos estos edificios a cargo de una Junta, formada por el Gobernador Civil de la provincia, el Corregidor de la Corte y tres individuos nombrados en representación de los acreedores del Estado. La Junta determinaría el mejor destino para cada inmueble, ya fuesen (Art. 2): «Cuarteles cómodos y ventilados en que pueda alojarse una guarnición de 10 hombres de infantería y 20 de caballería; [...] Hospitales y cárceles; [...] Nuevas calles, y ensanches de las actuales; [...] Plazas y mercados de nueva planta; [...] La misma Junta meditará y propondrá también cuáles de las propiedades que resulten sin aplicación pueden enajenarse a particulares» „32.

Interesa destacar que, por el momento, el citado decreto no manifestaba todavía una preocupación por el valor histórico-artístico de estos inmuebles. Sólo en el último párrafo del Art. 2 podemos adivinar una mínima y velada alusión a los edificios que hubiesen de conservarse por motivos de arte o historia ${ }^{33}$. En cualquier

\footnotetext{
${ }^{31}$ Así lo reconocía el propio Juan Álvarez de Mendizábal en la exposición del R. D. de 25 de enero de 1836: «Si estos edificios continúan como hoy se encuentran, poca utilidad puede esperarse de ellos en beneficio de los acreedores del Estado, porque las mezquinas cantidades que particulares ó corporaciones ofrecen pagar por alquileres apenas bastan para satisfacer los crecidos gastos de conservación y reparos, mientras que demolidos totalmente unos y reformados otros, tendrán inmediata aplicación estos y los terrenos que resulten de aquellos para objeto de interés general y particular, al paso que proporcionan ensanches y mejoras a la población".

${ }^{32}$ R. D. de 25 de enero de 1836, publicado en Gaceta de Madrid, no 397, el martes 26 de enero de 1836

${ }^{33}$ En tanto, las necesidades económicas del Gobierno le llevaban a tratar de agilizar ventas, como se observa en el R. D. 30 de agosto de 1836, por el que entraban a formar parte del Tesoro de la Nación todos los productos obtenidos de la venta de edificios, terrenos y objetos de las comunidades suprimidas, entre los que se encontraban «los productos que rindan en venta las campanas de todas las iglesias y monasterios» así como «de todas las alhajas, muebles y enseres» sobrantes una vez aplicadas las exenciones pertinentes.
} 
caso, poco después la medida se extendió al resto de provincias, solicitándose a las autoridades provinciales la elaboración de un informe sobre los edificios y conventos de sus territorios, atendiendo al estilo arquitectónico, mérito artístico y destino más oportuno ${ }^{34}$.

\section{LA GESTIÓN DEL PATRIMONIO DESAMORTIZADO. EL DESTINO DE LOS CONVENTOS SUPRIMIDOS EN MURCIA}

La aplicación de los inmuebles desamortizados a fines públicos tuvo, por tanto, distintas fórmulas. En ocasiones, los edificios fueron ocupados por la propia administración, como ocurrió frecuentemente con las oficinas de Hacienda o las dependencias de las Diputaciones y del Gobierno Civil. Otras veces fue el ejército quien se instaló en los viejos edificios conventuales, adaptándolos a sus necesidades $^{35}$. En las provincias, muchas instituciones culturales y benéficas, como escuelas, institutos, hospitales u hospicios, se beneficiaron de estos espacios. Cuando los edificios amenazaban ruina o requerían de grandes inversiones, la solución más frecuente era su derribo.

Como señala Bello, en muchas ocasiones los intereses del Gobierno y de las provincias se vieron enfrentados. A éstos últimos solía interesar la conservación y reutilización de los edificios, pero con esta solución la Administración central veía disminuidos sus ingresos. Por eso las cesiones se realizaban si se cumplían unas determinadas condiciones: que el edificio se adecuase al propósito que se destinaba, que no estuviese designado para la venta o prometiese mayores réditos económicos, y que se aceptase el pago de un canon ${ }^{36}$.

La cesión de los inmuebles era beneficiosa socialmente y, de hecho, muchos diputados veían en este proceso una oportunidad para la modernización de las retrasadas instituciones culturales españolas ${ }^{37}$. Sin embargo, los intereses económicos solían prevalecer sobre el resto. El trámite para la para la cesión era lento, y la urgencia por hacerlos rentables dio lugar a una política de derribos demasiado

\footnotetext{
${ }^{34}$ Josefina Bello toma esta noticia de una orden enviada en el mes de febrero a todos las intendencias (A.H.N. Hacienda, leg. 3638). Sin embargo, en el R.D. de 13 de septiembre de 1836, por el que se forman las juntas para la venta de los edificios enajenados, nada se menciona al respecto, señalándose tan solo que se suprimía la junta creada en Madrid y que el destino de estos edificios pasaba a depender, en todas las provincias, de las nuevas juntas para la venta. Estas juntas estuvieron en funcionamiento hasta 1840, año en que fueron suprimidas mediante R.O. de 18 de diciembre de 1840.

${ }^{35}$ Resultan de gran interés las noticias recogidas por Josefina Bello en relación a esta ocupación de conventos por parte de los militares, relatando cómo en muchos de ellos la ocupación se llevó a cabo sin ningún respeto o consideración sobre su valor artístico, ilustrando los destrozos producidos por las tropas en monumentos tan significativos como San Esteban de Salamanca, Santo Domingo de Valencia o los monasterios burgaleses de la Viña, San Agustín, la Merced o Trinitarios, éste último privado de su portada con el fin de levantar un fortín. BELLO, J., Frailes, intendentes y políticos. Madrid, Taurus, 1997, pág.

${ }^{36}$ Ibídem, pág. 242-243.

${ }^{37}$ BOLAÑ̃, M., Historia de los museos en España, Gijón, Trea, 1997, pág. 188.
} 240-241. 
generalizada - los solares podían ser puestos en venta, o aplicarse a la mejora urbanística ampliando calles o creando nuevas plazas-. En este sentido, es paradigmático lo ocurrido en Madrid, donde se demolieron conjuntos muy significativos - San Felipe el Real, La Trinidad, La Merced, Basilios, Capuchinos de la Paciencia y Capuchinos del Prado-. Estas actuaciones indiscriminadas llevaron la alarma al seno de la Academia de San Fernando, que trató de sensibilizar del problema al Gobierno y a las Cortes en noviembre de 1836. Los académicos clamaban por la conservación de tan insignes monumentos, y para ello solicitaron que fuese obligatorio consultarles antes de ejecutar cualquier demolición. El sentir de la corporación debía ser acorde a lo que en esas fechas manifestaba Pedro de Madrazo, y que recoge Gaya Nuño en un artículo en Revista Española: «No abogaré por los conventos en sus corporaciones, por el sinúmero de religiosos cuya desproporción con respecto al número de habitantes de nuestras poblaciones movió al Gobierno a su extinción, no ciertamente; pero sí clamaré por la conservación de los buenos edificios que esas corporaciones ocupaban [...] Sean demolidos los que en vez de ornato sólo dan a la población un aspecto lúgubre y miserable, con sus prolongadas y rústicas tapias, y que no ofrecen la menor curiosidad artística en su fábrica, pero de ningún modo los conventos de san Felipe el Real, la Merced, la Trinidad y otros de mérito» 38

En la provincia de Murcia, el destino más común de los edificios desamortizados fue su reutilización para fines públicos; por encima incluso de los derribos y las nuevas construcciones ${ }^{39}$.

Estos viejos edificios constituían una carga para el comprador particular, debido a los grandes gastos de mantenimiento y a su difícil aprovechamiento. Por otra parte, a diferencia de lo en ese momento que ocurría en urbes como Madrid o Barcelona, donde se vivía una espiral constructiva que atraía a los especuladores, en provincias como Murcia lo que realmente tenía valor eran las tierras. Fue, por tanto, la falta de postores lo que ocasionó que casi todos los edificios desamortizados de Murcia quedasen en manos de la Administración. Como señala Blanco, solo dos inmuebles, el de Agustinos de Cartagena y el de la Merced de Murcia, interesaron a los compradores ${ }^{40}$.

El Convento de Santa Isabel es un buen ejemplo de la aplicación de los inmuebles para mejoras urbanas. Ubicado en plena traza medieval, laberíntica y abigarrada, su derribo en 1836 dio lugar a una amplia plaza que pronto se convirtió en centro de la vida social murciana. Solución muy común en las transformaciones urbanísticas de este siglo, en el que se pasa de la ciudad-convento a la ciudad moderna ${ }^{41}$.

${ }^{38}$ GAYA NUÑO, J.A., La arquitectura española en sus monumentos desaparecidos. Madrid, Espasa Calpe, 1974, pág. 19, en BELLO, J., óp. cit., pág. 255.

${ }_{39}$ NICOLÁS GÓMEZ, D., Arquitectura y Arquitectos del siglo XIX en Murcia. Murcia, Ayuntamiento de Murcia, Colegio Oficial de Arquitectos de Murcia, 1993, pág. 227.

40 VILLAVONA BLANCO, Mạ , La desamortización eclesiástica en la Provincia de Murcia (18351855). Murcia, Real Academia Alfonso X el Sabio, 1993, pág. 48.

${ }^{41}$ NICOLÁS GÓMEZ, D., óp. cit., pág. 227. 


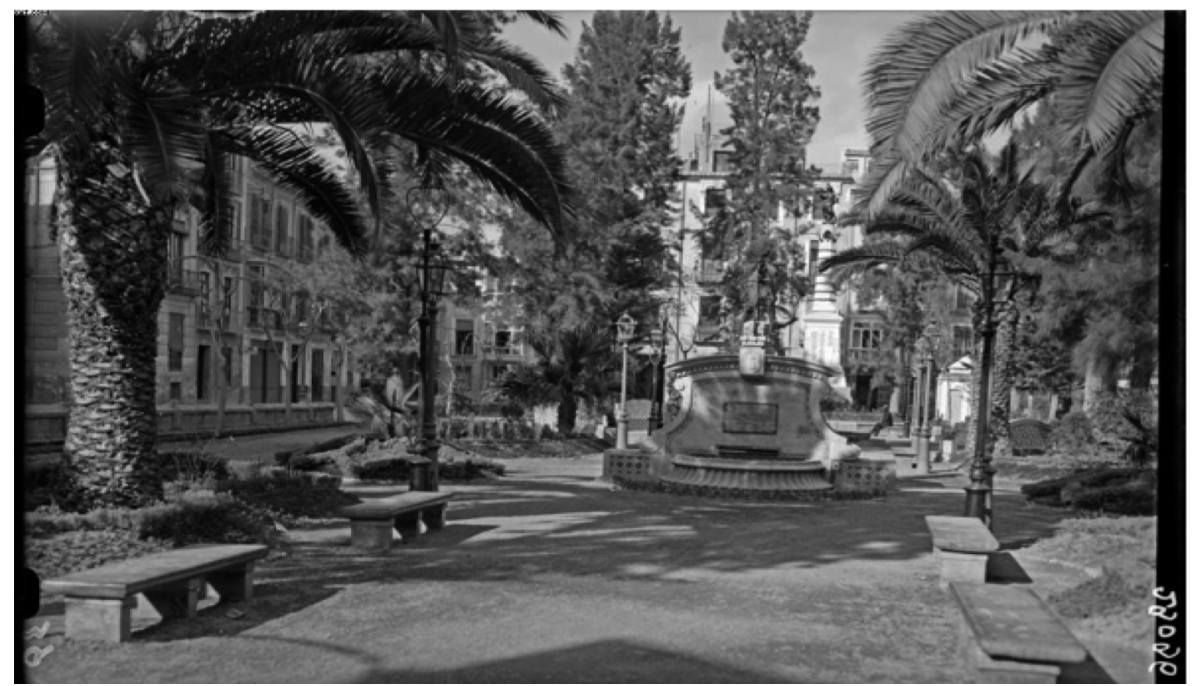

Plaza de Santa Isabel. Antonio Passaporte, Fecha de la toam 1927-1936. Fototeca del Instituto de Patrimonio Cultural de España. Archivo Lotty. LOTY-05597

Del resto de edificios, conocemos algunos informes realizados por los miembros de la Real Sociedad Económica de Amigos del País de Murcia ${ }^{42}$. Se trata de documentos fechados entre enero y agosto de 1837, un periodo en el que se acentúa el interés del gobierno por los bienes nacionalizados, como demuestra la creación, mediante R. O. de 27 de mayo de 1837, de unas Comisiones Provinciales Científico Artísticas, cuyos objetivos eran la formación de inventarios y el traslado y conservación de los objetos de mérito a lugares apropiados, como museos o bibliotecas ${ }^{43}$.

En el caso que nos ocupa, la Real Sociedad Económica de Murcia es una institución fundamental. Fue la responsable, en virtud de la R.O. de 29 de julio de 1835, de «examinar, inventariar y recoger cuanto contengan los archivos y bibliotecas de los monasterios y conventos suprimidos, y las pinturas, objetos de escultura u otros que deban conservarse» ${ }^{44}$; y, en mayo de 1937, se le encomendó que formase la Comisión Provincial Científico Artística de Murcia ${ }^{45}$.

42 Dora Nicolás recoge un informe de la Real Sociedad Económica de Amigos del País de Murcia, emitido el 13 de agosto de 1837, y conservado en el Archivo Municipal de Murcia, leg. 2828. NICOLÁS GÓMEZ, D., óp. cit., pág. 229. Por su parte, en el archivo de la corporación podemos encontrar otros informes sobre el mismo asunto fechados en 19 de enero, 28 de febrero y 19 de julio de 1937, respectivamente. En cualquier caso, no existen grandes variaciones respecto a lo recogido por la citada autora. Archivo de la Real Sociedad Económica de Amigos del País de Murcia (ARSEAPM), Fondo Real Sociedad Económica, 1837-01-19 / 1837-07-19.

${ }^{43}$ R. O. de 27 de mayo de 1837, publicada en Gaceta de Madrid, no 907, el domingo 28 de mayo de 1837.

${ }^{44}$ R.O. de 29 de julio de 1835, publicada en Gaceta de Madrid, no 217, el martes 4 de agosto de 1835.

${ }^{45}$ Sobre la Comisión Científico y Artística de Murcia y su inmediata sucesora, la Comisión Provincial de Monumentos, MARTÍNEZ PINO, J. «La Comisión Provincial de Monumentos de Murcia. Precedentes y actuaciones (1835-1865)», Espacio, Tiempo y Forma, Serie VII, Historia del arte, ำ 18-19, 2005-2006, págs. 135-162. 
El primero de los documentos mencionados es una contestación a un oficio de la Junta de Enajenación de la provincia, en la que se recoge el parecer de la Económica sobre el mejor destino de los edificios suprimidos. Quitando una serie de edificios aprovechables a otros fines - Convento de San Francisco para oficinas provinciales; San Juan de Dios como hospital; la Trinidad cono cuartel; la Purísima par dependencias de la Real Sociedad; y Santa Catalina para un Lazareto-,

«Todos los demás, en sentir de esta comisión deben venderse [...] por ser el único medio que puede reportar más utilidad efectiva al Estado. Porque a la verdad, cortísima sería la cantidad que produciría la venta para su derribo, porque esta población afortunadamente no es tan insalubre que necesite de mas ventilación, pues que la altura general de sus edificios no se la impide ni le faltan tampoco plazas para su mayos desahogo. [...] no así vendiéndolos como están, pues en este caso valoran más los otros materiales, se pagarán los solares y se emplearán por más tiempo jornaleros, porque todo comprador derribará y reedificará».

Fechado el 19 de enero de 1937, llama la atención que en su dictamen no hay cabida a razones históricas 0 artísticas ${ }^{46}$.

No ocurre lo mismo con el documento fechado en julio del mismo año. Si bien el destino previsto para muchos de estos edificios no difiere de lo apuntado meses atrás, se observa ahora un juicio estético en sus argumentos, e incluso un posible aprovechamiento artístico. Veamos:

«El Convento de San Francisco por la bella arquitectura de su obra nueva, magnífica escalera de dos ramales colocada en medio de dos patios decorados [...] su orden arquitectónico, que puede servir como de escuela a los jóvenes que se dediquen a este estudio; debe conservarse destinándolo para oficinas provinciales.

Santo Domingo, por sus grandiosos salones, bellísimo patio y bóvedas, extensa capacidad y fortaleza de su obra puede destinarse para casa Coliseo.

La Merced, aunque el orden arquitectónico de su patio pudiera servir de modelo y estudio para los que se dedican a la arquitectura, careciendo lo demás de él de objeto alguno que recomiende su conservación y por otra parte no siendo susceptible para ninguna clase de establecimiento pudiera habilitarse en el casa particulares en beneficio del Erario, reservando su magnífica iglesia, que tanto por su hermosura como por su localidad puede servir de ayuda de parroquia dando culto a la imagen de Ntra. Sra. de los Remedios, a quien los murcianos profesan una antigua devoción.

San Agustín. Este edificio no es de los más aventajados por su arquitectura, pero sí por su mucha localidad,[...] muy ventilado, tanto por la espalda que cae a la huerta como por la fachada que da a una anchurosa plaza, quizá la mayor de esta capital puede destinarse con bastante proposición para un cuartel, y su iglesia que fuera de la de la catedral es la más capaz y que su espaciosa nave y grande altura la dan un aspecto majestuoso, debe destinarse para reunión del publico en actos civiles o religiosos en que no pueda citarse a la intemperie ${ }^{47}$.

\footnotetext{
${ }^{46}$ ARSEAPM, Fondo Real Sociedad Económica, 1837-01-19.

${ }^{47}$ En la señalada versión del Archivo Municipal de Murcia se consideraba que la iglesia, por su monumentalidad, debería sustituir a la vecina de San Andrés.
} 
La Trinidad: Este convento que se haya en el entorno de Levante de la ciudad no tiene otra particularidad que el patio adornado de columnas de mármol; su templo está a medio construir y todo ello no puede ser aplicable más que o para cuartel, por estar muy ventilado con una gran plaza a su frente y casi en la misma huerta o para formar casas particulares en beneficio del vecindario y del Erario.

Colegio de la Purísima: este pertenecía a los regulares franciscanos, aunque de solidez no es tan capaz como los conventos, disfruta de buenas vistas al paseo del Malecón y orillas del Segura por la parte del mediodía y por la del norte a lo más público de la ciudad. En 1822 fue concedido por S.M. a esta Sociedad Económica para establecer en él sus enseñanzas, y lo ha sido nuevamente en el año últimos, aunque pagando por él un módico alquiler.

San Juan de Dios: este convento tiene bastante solidez, mucha capacidad buena ventilación y propio para el destino que tiene de hospital general; sus grandes y magníficos salones construidos de mármol para el objeto, sus altas bóvedas la reunión a los edificios destinados para la cura del venéreo y convalecencia, con habitaciones adecuadas para los asistentes, una capilla muy proporcionada, que es una graciosa rotonda, su magnífica escalera, grande patio y demás que le adornan no dejan que desear para el objeto a que está destinado.

Santa Teresa: este convento en nada es ventajoso, sin capacidad ni proporción para establecimiento público [...]. Solo puede ser aplicable para casas particulares.

San Felipe: este edificio es bueno en cuanto a solidez, pero no presenta [¿obra?] interesante a las artes, su capilla sería utilísima si se agregase a la iglesia parroquial de Sata. Eulalia, de quien solo la divide una pared, y lo demás convertirlo en casa particulares ${ }^{48}$.

El informe conservado en el Archivo Municipal de Murcia, recogido por Dora Nicolás, nos amplía la información a otros conventos relevantes: el de Verónicas, que «no presenta belleza alguna que le haga digno de conservarse, su situación en la plaza de las verduras le constituyen en el caso de ser destinado por casas, con grande beneficio del Estado por el valor que tiene las que lindan con él»; y el Convento de San Jerónimo, situado a las afueras de la ciudad, «construido en 1507, sus grandes bóvedas, magníficos aposentos, suntuosa escalera y más que todo su ventilación por hallarse en una altura y sin edificio alguno en sus alrededores, debe destinarse para Lazareto de observación y aún si se quisiera a enfermería» ${ }^{49}$. Es curioso, además, que a propósito del señalado Convento de San Francisco, se utilice incluso el término de museo para referirse a su uso por parte de estudiantes de arquitectura — «...puede servir de un museo, donde los jóvenes puedan estudiar la construcción de toda clase de bóvedas y arcos...»-

${ }^{48}$ ARSEAPM, Fondo Real Sociedad Económica, 1837-07-19.

49 NICOLÁS GÓMEZ, D., Óp. cit., págs. 229-231. Sobre la historia y destino del Monasterio de Verónicas, RIQUELME OLIVA, P., "Consecuencias de la política liberal en la Comunidad de Verónicas (Siglo XIX)», en AGÜERA ROS, J.C., et. alii, El Monasterio de Santa Verónica de Murcia. Historia y Arte, Murcia, Espigas, 1994, págs. 57-71. 


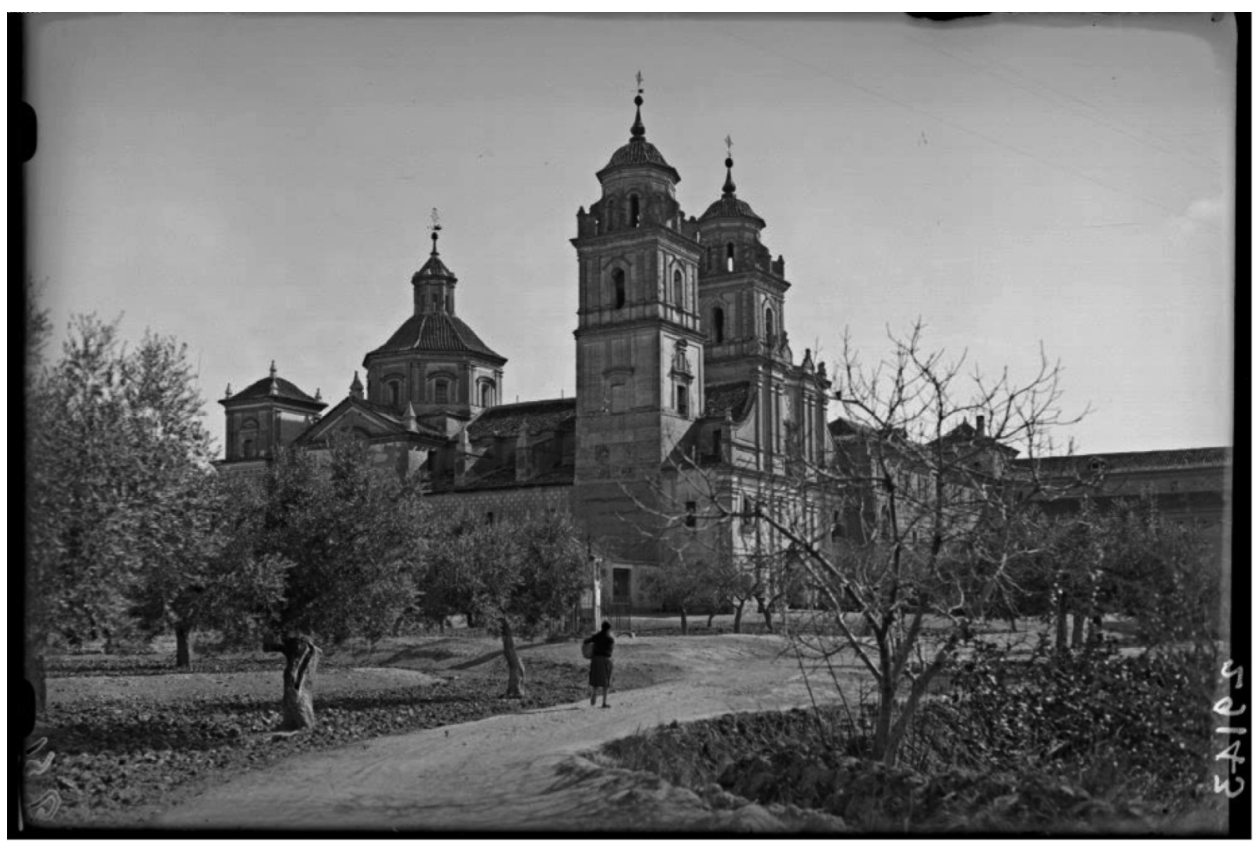

Monasterio de los Jerónimos. Antonio Passaporte. Fecha de la toma: 1927-1936. Fototeca del Instituto de Patrimonio Cultural de España. Archivo Lotty. LOTY-05643

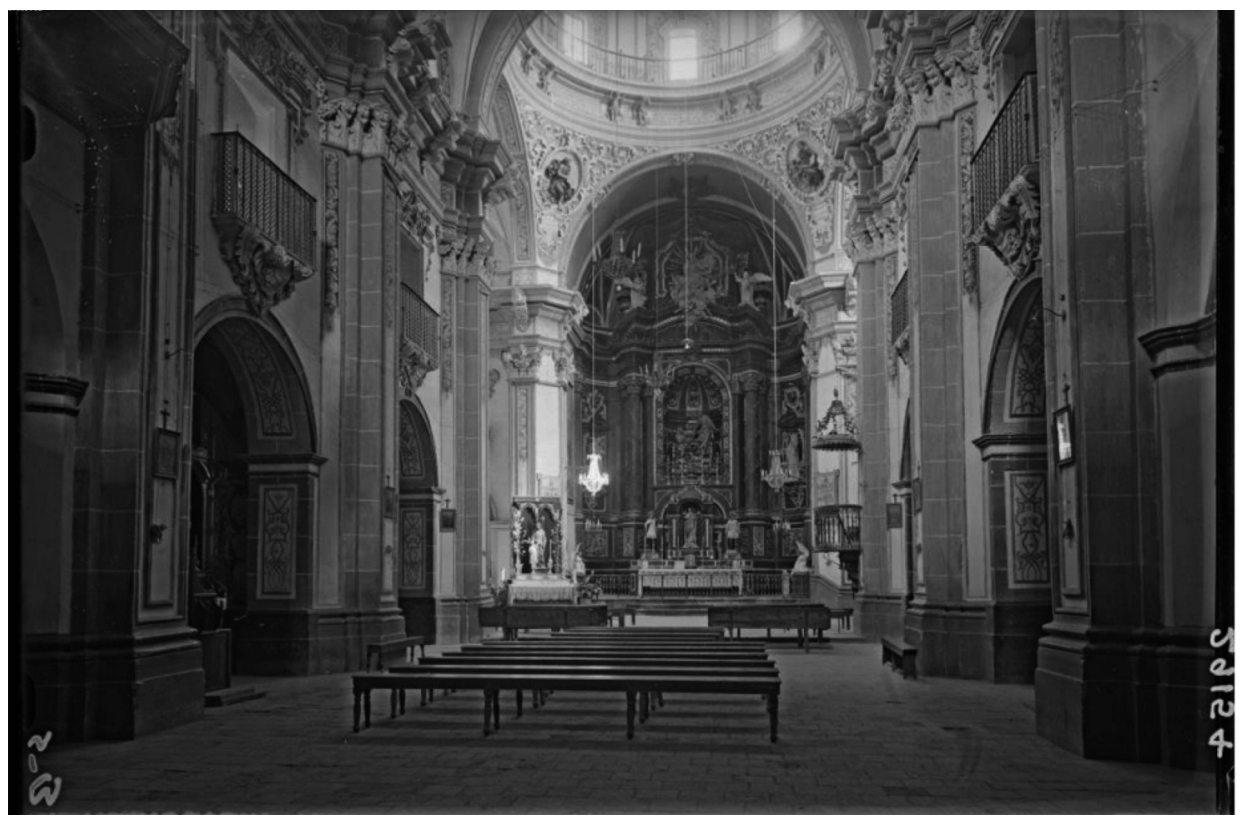

Interior de la iglesia del Monasterio de los Jerónimos. Antonio Passaporte. Fecha de la toma: 19271936. Fototeca del Instituto de Patrimonio Cultural de España. Archivo Lotty. LOTY-05654 


\section{CONCLUSIONES}

Como hemos visto, el aprovechamiento público de los edificios desamortizados estuvo siempre en un segundo plano entre los objetivos del Gobierno. El fin de estos inmuebles fue casi siempre el mismo: demolición y reedificación de casas en sus solares. Durante los años siguientes a la desamortización de Mendizábal, el propio Gobierno alentó este procedimiento ordenando derribos y enajenando solares a la incipiente burguesía provincial ${ }^{50}$.

No obstante, la escasa demanda alargó durante años este proceso, permitiendo que, en tanto, calase una nueva sensibilidad hacia los bienes históricos y artísticos y su conservación. Los años siguientes verían surgir los primeros museos y bibliotecas provinciales; $y$, a partir de 1844, la puesta en marcha de una verdadera administración del patrimonio con la creación de las Comisiones Provinciales de Monumentos. Estas corporaciones fueron las encargadas de inventariar, catalogar y gestionar un patrimonio que iba más allá de los bienes procedentes de los conventos desamortizados. Fueron también las responsables de velar por la conservación y adecuado uso de los inmuebles históricos, entre ellos muchos de estos edificios religiosos.

Los años tratados inauguran un periodo en el que, a través de la normativa, se observa un creciente interés por nuestro patrimonio. Se trata, sin embargo, de un periodo complejo, plagado de loables iniciativas, pero también de flagrantes dejaciones; en el que no siempre se puso gran empeño en el cumplimiento de las leyes, y mucho menos se dotó adecuadamente a los responsables de su conservación.

${ }^{50}$ NICOLÁS GÓMEZ, D., óp. cit., pág. 227. 